\title{
The transfer of information across sensory modalities*
}

\author{
RONALD W. SHAFFER $\dagger$ and JAMES HOWARD \\ Western Washington State College, Bellingham, Washington 98225
}

\begin{abstract}
Previous research has shown that $\mathrm{Ss}_{\mathrm{s}}$ can recognize, classify, or identify the same nominal stimuli when presented via different sensory modalities. Two hypotheses, the mediational and invariant features, have been forwarded in an attempt to account for this ability. The present study was designed so that the reliable transfer of either specific or conceptual sources of information across sensory modalities would provide support for the invariant-feature hypothesis. Evidence was obtained for the transfer of both sources of information when the stimulus modality was not changed. However, neither source of transfer was evident when the stimulus modality was changed; thus, no support for the invariant features hypothesis was obtained in the present study.
\end{abstract}

The ability of organisms to recognize, classify, or identify stimuli via a sensory modality different from that originally experienced is well documented (see Gibson, 1969, Chap. 11; Wright, 1970, for reviews). Moreover, Birch and Lefford (1963) have shown that the ability to "integrate" information from various sensory modalities improves with age-experience. How the organism behaves to achieve equivalence of intersensory analogues is not apparent, however.

Two disparate, although not mutually exclusive, positions have been taken to account for the above findings: a mediational hypothesis and an invariant features hypothesis. The point of division between the alternatives is over the locus of the stimulus elements that provide for the functional equivalence of intersensory stimuli. The mediational position assumes that intersensory stimulus equivalence is achieved by S-supplied mediational responses (stimuli), while the invariant features hypothesis assumes that $S$ responds directly to supramodal stimuli, higher-order stimuli invariant to particular sensory modality (Gibson, 1966).

The mediational position is consistent with the assumption that the same nominal stimulus when first presented to different sensory systems results in functionally different stimuli for the organism; hence, the need for $S$ to add some common (mediating) property. Gibson's suggestion, alternatively, does not have the organism add information that did not exist in the input; rather, the organism is viewed as achieving correspondence with features or patterns of information not restricted to specific sensory systems.

While the mediational hypothesis has been invoked as a post hoc explanation of intersensory equivalence of stimuli (Blank \& Bridger, 1966; Gaydos, 1956; Holmgren, Arnoult, \& Manning, 1966), there have been no systematic attempts to show acquired equivalence of intersensory stimuli supported by learned common responses to intersensory analogues. That such studies

\footnotetext{
* A portion of this pader was presented at Rocky Mountain Psychological Association, Las Veras, 1973.

tRequests for reprints should be sent to Ronald W. Shafier, Department of Psychology, Western Washington State College, Bellingham, Washington 98225.
}

have not been conducted is in no doubt due, in part, to the fact that such training would also provide $S$ opportunities to learn about dimensions of information invariant to input modality, and also due to the argument that associatively acquired mediational responses are epiphenomenal.

Since "building in" mediational responses will not converge on either interpretation, the only available avenues open for critical testing are to: (a) examine intersensory performance under conditions where mediational responses to intersensory analogues are made improbable, if not impossible, or similarly, (b) provide empirical support for sources of intersensory transfer that by their very nature cannot be "carried" by associatively acquired responses. Two, functionally analogous, research strategies fall into the first category. One is where Ss' behavior is observed with stimuli via a sensory modality not previously functional (Riesen, 1947; Siegel, 1953; Senden, 1960). More specifically, the visual behavior of the newly sighted, resulting from either removal of congenital cataracts or cessation of experimentally imposed visual deprivation, is observed to determine if Ss can transfer previously learned information, acquired via other sensory systems. Although this research strategy is reasonable on the surface, it has not produced unambiguous findings (Krauthamer, 1959). A second procedure is to give Ss practice with unfamiliar form stimuli via one sensory modality, followed by a task where the "same" stimuli are presented via another modality (e.g., Gaydos, 1956; Holmgren, Arnoult, \& Manning, 1966; Shaffer \& Ellis, in press), with the assumption that the use of stimuli not previously experienced by $S$ minimizes the likelihood of common mediating responses being associated to intersensory analogues. This research strategy is used in the present study by training Ss to classify unfamiliar dot patterns into a priori defined conceptual classes, presented either haptically or visually, followed by a similar task where the stimulus analogues plus other patterns are presented via the other modality, visually or haptically, respectively. The transfer of specific information across modalities is given by S's 
performance on training patterns when contrasted to new within-class patterns.

The second research strategy outlined above (b) is also used in an attempt to establish the validity of the invariant features hypothesis. It is the thesis of the present study that a demonstration of the transfer of stimulus learning across sensory modalities (either acquired information that would serve to enhance discriminatory skills or knowledge about population characteristics) forces the conclusion that $\mathrm{Ss}$ are responding to sources of information invariant to sensory systems. This assertion is based on the assumption that if Ss learned to discriminate among a set of stimuli given via one modality, haptic exploration, for example, and if these modified discriminatory skills transferred to a second task where the "same" stimuli were presented via another modality, visual, then it must, by necessity, follow that Ss were responding to invariant sensory features, since associations learned during the first haptic task, if any, could not logically enhance subsequent visual discriminatory performance, unless, of course, there were some common stimulus elements contained directly in the input.

At a general level, stimulus leaming can be subdivided by what $\mathbf{S}$ learned about specific stimulus features, compared with acquired information about population characteristics. The former is generally referred to as stimulus discrimination, while the latter source of stimulus learning is called schema learning (Bartlett, 1932; Evans, 1967; Posner, 1969). A schema is a concept or population parameter that defines the common, redundant, or invariant properties within a stimulus class. The present study employs the operations devised by Posner and Keele (1968) for investigating intrasensory transfer of schema learning, in an intersensory transfer paradigm, thus affording a test of the invariant features hypothesis.

In summary, two strategies are used to determine whether there are stimulus-input properties invariant to sensory systems, one by observing intersensory transfer performance with unfamiliar stimuli, and secondly, by determining whether the transfer of stimulus learning, across sensory modalities, can occur.

\section{METHOD}

\section{Subjects}

Fifty-two Ss in blocks of four were randomly assigned to each of a like number of treatment conditions. The Ss obtained additional credit in an introductory psychology course at Western Washington State College for their participation in the experiment.

\section{Stimuli and Apparatus}

The stimuli consisted of: three 9-dot patterns, designated class prototypes (CP); six 7-bit distortions $\left(\mathrm{V}_{7}\right)$ derived from each of the three CPs; two 5-bit distortions of each $\mathrm{CP}\left(\mathrm{V}_{5}\right)$; and three random 9-dot patterns ( $R$ ). A CP and its $V$ represent a schema class or conceptual class (Posner \& Keele, 1968). Xeroxed copies of the dot patterns were obtained from Posner and Keele (1968) and detail construction procedures are given in Posner,
Goldsmith, and Welton (1967). Briefly, a V was generated by randomly moving each of the 9 points on a designated $C P$ pattern, while a 7-bit $\mathrm{V}$ was allowed to move a greater distance from the original point than a 5-bit $V$. The generation rule for each V within a schema was reiterative, since all Vs were derived from a common prototype. Accordingly, each $V$ may be viewed as representing some space in the multidimensional space about a CP.

The stimuli for visual presentation were photographed on 35-mm slides and presented onto a rear-projection screen via a Kodak (Carousel 650) projector. The stimuli to be presented haptically were constructed by the following procedure: (1) projecting the slides onto paper sheets and marking the projected dots, (2) attaching the marked sheets onto $12.7 \mathrm{x}$ $12.7 \mathrm{~cm}$ plywood mounts, and (3) driving finishing nails through each dot to a uniform height of $1.9 \mathrm{~cm}$ above the surface of the mount.

The apparatus consisted of an $81.2 \times 121.9 \mathrm{~cm}$ black panel with a $7.6 \times 12.7 \mathrm{~cm}$ rear-projection screen located to the right center of the panel. On the bottom center of the panel was a hood sloped towards the $S$ in such a way that the $S$ could manipulate the raised dot patterns with both hands while at the same time not being able to view them. Between the viewing screen and the hood were three colored feedback lights, red, green, and yellow, arranged vertically. The duration of the feedback lights as well as the sequencing and duration of the projector were controlled by a BRS solid state unit.

\section{Design}

The four treatment conditions were differentiated only by the sensory modality by which the dot stimuli were presented in the training and transfer task. Save for the stimulus modality parameter, the training-transfer task closely parallels Experiment III of Posner and Keele's (1968) study, where the learning of schematic information was inferred by $S$ 's transfer task performance on CP when compared to new 5-bit Vs.

Two groups of Ss received classification training with visually presented stimuli; one group continued with visual dot stimuli in the transfer classification task (V-V), and the other haptically explored the dot stimuli in the transfer classification task (V-H). The remaining two groups received training with haptically presented stimuli, one receiving a haptic transfer task $(\mathrm{H}-\mathrm{H})$, and the other a visual transfer task $(\mathrm{H}-\mathrm{V})$. The two intrasensory groups, $\mathrm{V}-\mathrm{V}$ and $\mathrm{H}-\mathrm{H}$, served as controls to which the two intersensory groups, V-H and H-V, could be contrasted. Since pilot data had indicated that visual presentation resulted in fewer training trials to asymptotic performance, when exposure duration was equated, no direct comparisons between unlike training modality conditions were possible. Similarly, no direct comparisons of absolute transfer performance were possible for the like modality training conditions that received unlike stimulus modalities in transfer. Consequently, all comparisons between groups were based on relative transfer performance on the different stimulus types, old $V_{s}, C P$, new $V_{5} s$ and $V_{7} s$. Following Posner and Keele (1968), evidence for schema learning was obtained by contrasting transfer performance on $\mathbf{C P}$ with that of new $V_{s} s$, since both stimulus types have been shown to be physically (Posner, Goldsmith, \& Welton, 1967; Posner \& Keele, 1968) as well as psychophysically (Posner, Goldsmith, \& Welton, 1967) equidistant to the training 7-bit Vs. Accordingly, superior transfer performance on $\mathrm{CP}$ singles out the prototype as unique and not consistent with expectations of stimulus generalization (Posner \& Keele, 1968). Additionally, Posner and Keele show that the average physical distances between 7-bit Vs are greater than the distances between 7-bit Vs when contrasted to CP and 5-bit Vs. Although 7-bit new Vs are included in the present study as transfer patterns for comparability to the Posner and Keele study, they are not used in the assessment of schema learning.

Assessments of the transfer of specific information is made 
Fig. 1. Mean number of correct responses for the four training conditions (plotted points) are derived from scores of all Ss who completed 14 trials, plus maximum "pseudoscores" projected forward for all Ss who completed two consecutive errorless trials prior to completing the 14 anticipation trials.

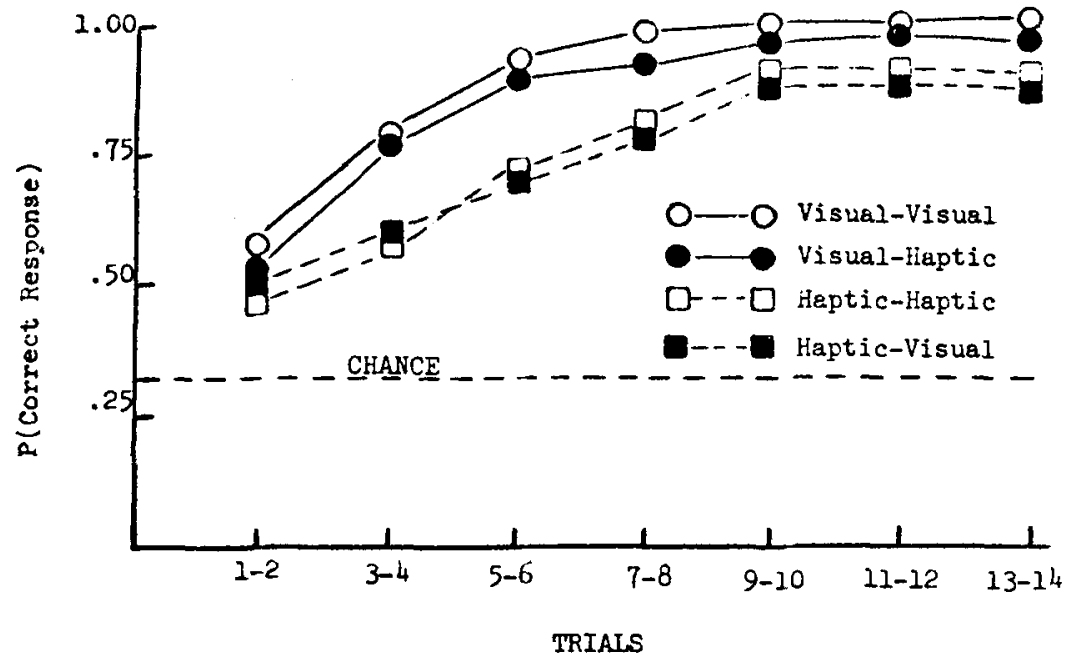

RESULTS

difficult in the present design, since the transfer tasks do not require $S s$ to distinguish old training patterns from new within-class patterns. However, if, in the transfer task, Ss sort old Vs better than new within-class patterns, then it must follow that Ss retained specific information about the old training patterns. Evidence for such transfer-retention both within and between sensory modalities would imply that the specific pattern information is encoded similarly when presented visually or haptically.

\section{Training Procedure}

Twelve $V_{7} s, 4$ from each schema class, were presented during training, one at a time to each of the four groups. The Ss were instructed to observe the $12 \mathrm{Vs}$ either visually or haptically and to note the correct classification, as given by illumination of one of the colored lights, for the first trial, and, thereafter, to anticipate the correct classification by saying aloud the appropriate color code. During the first observation or study trial, each $\mathrm{V}$ and its correct feedback light was presented for $8 \mathrm{sec}$, followed by a 3-sec "time-out." The Ss were informed when all 12 Vs had been presented and were instructed to respond to all subsequent Vs, even if they had to guess. Thereafter, each $V$ remained on the screen or in the holder unaccompanied by the feedback light until $S$ said one of the three colors. The E selected the correct feedback light for the next $V$ during the time-out and started the 8-sec observation feedback cycle as soon as $\mathrm{S}$ gave a color response. Training was continued until either 2 consecutive errorless trials or 14 anticipation trials were achieved, whichever came first.

\section{Transfer Procedure}

All Ss received the same stimuli in the transfer task, the only variable differentiating the four groups being the relationship between the training-transfer sensory modality. The transfer task replicated Posner and Keele's (1968) Experiment III, except for the omission of Day 2 response measures and that RT were not taken. Briefly, Ss were asked to sort the transfer stimuli into one of three color-designated groups according to what they learned in the training task. The transfer stimuli were 2 randomly chosen $V_{7} s$ from training, 2 new $V_{5} s$ and $V_{7} s$ from each schema class, the CP of each schema class, and 3 Rs, making a total of 24 stimuli. The 24 stimuli were presented twice, and Ss were instructed to categorize each dot pattern without feedback.

For the $\mathrm{H}-\mathrm{V}$ and $\mathrm{V}-\mathrm{H}$ conditions, the intersensory stimulus equivalents were presented such that the top of the dot patterns, presented visually, corresponded with the most distant aspects of the patterns when presented haptically. The forms for both the training and transfer task were placed horizontally in a holder behind the hood by $\mathrm{E}$ for haptic exploration.

\section{Training}

In order that a comparison of within-modality group, $\mathrm{V}-\mathrm{V}$ and $\mathrm{H}-\mathrm{H}$, could be made to their respective between-modality counterparts, $\mathrm{V}-\mathrm{H}$ and $\mathrm{H}-\mathrm{V}$, respectively, unconfounded by differences in training, it must be shown that no differences in performance exist between like-modality training conditions.

Examination of Fig. 1 shows the like modality training conditions very nearly identical in training acquisition rates. Moreover, an analysis of number of correct responses for Groups V-V and V-H across the 14 training anticipation trials did not yield a reliable difference, $F(1,24)=2.40, p>.05 ;$ moreover, the Groups by Trials effect did not yield a reliable difference, $F(12,312)=.66$. Comparable analysis for Groups $\mathrm{H}-\mathrm{H}$ and $\mathrm{H}-\mathrm{V}$ also yielded no reliable differences, $F(1,24)=.06$ and $F(12,312)=.66$, respectively. Both analyses were computed on all 14 trials by projecting the criterion of two errorless trials before the 14-trial cut-off. The mean trials to two errorless trials for the $\mathrm{V}-\mathrm{V}, \mathrm{V}-\mathrm{H}, \mathrm{H}-\mathrm{H}$, and $\mathrm{H} \cdot \mathrm{V}$ groups were $7.3,8.9,10.7$, and 12.0 , respectively. These intrasensory differences did not approach significance. The findings are commensurate with the assumption that like sensory modality groups were equivalent with respect to their learning rates, hence differences in transfer performance must reflect sensory modality parameters and not differences in degree of original learning. The mean percentage correct classifications for the four groups, V-V, V-H, H-H, and $\mathrm{H} \cdot \mathrm{V}$, at the end of training was $100,97.8,92$, and 87.9 ,

\section{Transfer}

Table 1 shows the mean percent correct by type of training-transfer stimulus for the four groups. An analysis of correct classification responses for the four groups by stimulus type yielded a significant groups effect, $F(3,48)=8.88, p<.01$, and a reliable stimulus forward asymptotic performances for all Ss who reached respectively. 
Table 1

Mean Percent Correct for the Four Groups as a Function of Transfer Stimulus Type

\begin{tabular}{ccccc} 
& $\begin{array}{c}\text { Old } \\
\text { 7-Bit } \\
\text { Varia- } \\
\text { Group }\end{array}$ & $\begin{array}{c}\text { Class } \\
\text { Proto- } \\
\text { type }\end{array}$ & $\begin{array}{c}\text { New } \\
\text { 5-Bit } \\
\text { Varia- } \\
\text { tion }\end{array}$ & $\begin{array}{c}\text { New } \\
7-B i t \\
\text { Varia- } \\
\text { tion }\end{array}$ \\
\hline Visual-Visual & 91.0 & 76.9 & 62.8 & 51.9 \\
Visual-Haptic & 62.8 & 60.9 & 67.3 & 46.2 \\
Haptic-Haptic & 83.3 & 71.8 & 69.2 & 57.1 \\
Haptic-Visual & 71.8 & 78.2 & 73.1 & 55.1 \\
\hline
\end{tabular}

type effect, $F(3,144)=14.88, p<.01$. The Group by Stimulus Type interaction was not reliable, $F(9,144)=$ $1.45, \mathrm{p}>.05$. In this analysis and in all succeeding analyses, the number correct for $\mathrm{CP}$ was doubled, since Ss had only one-half as many opportunities to sort CP when compared to the old and new 5- and 7-bit variations.

The transfer of specific information, as given by contrasting performance on $\mathrm{OV}$ to new 5-bit variations for Group V-V was evident, $t(12)=5.31, \mathrm{p}<.01$. However, as is reflected in Table 1, the performance to OV when contrasted to new 5-bit variations for Group V-H was not superior, $\mathrm{t}(12)=1.30, \mathrm{p}>.05$. The same pattern of findings was obtained with the haptic training groups: the intrasensory transfer of specific information was obtained for Group $\mathrm{H}-\mathrm{H}, \mathrm{t}(12)=3.1$, $p<.01$, while no evidence for such transfer for Group H-V was obtained, $\mathrm{t}(12)<1.00$.

Turning to the transfer of schema learning, Table 1 shows, for Group V.V, superior performance on CP when compared to new 5 -bit variations. This difference is reliable, $\mathrm{t}(12)=4.35, \mathrm{~F}<.01$, and is consistent with the findings of Posner and Keele $(1968,1970)$ and others (Strange, Keeney, Kessel, \& Jenkins, 1970). A comparison of the OV to CP for Group V-V did yield a reliable difference, $\mathfrak{t}(12)=2.61, \mathrm{p}<.05$. This latter comparison is consistent with Posner and Keele (1970) and Strange et al (1970). In contrast, both the CP vs new $\mathrm{V}_{5}$ and $\mathrm{CP}$ vs $\mathrm{OV}$ comparisons for Group V-H were not reliable, $t(12)<1.0$ for each. Test for evidence schema learning for Groups $\mathrm{H}-\mathrm{H}$ and $\mathrm{H}-\mathrm{V}$ show no reliable $\mathrm{CP}$ vs new $\mathrm{V}_{5}$ or $\mathrm{CP}$ vs $\mathrm{OV}$ comparisons.

\section{DISCUSSION}

In contrast to a number of studies that show evidence for the transfer of information across sensory modalities (e.g., Clark, Warm, \& Schumsky, 1972; Gaydos, 1956; Holmgren, Arnoult, \& Manning, 1956; Shaffer \& Ellis, in press), no evidence was obtained in the present study for the intersensory transfer of specific or schematic sources of information. The failure to observe the transfer of specific information across sensory modalities, as given by the comparable performance on old variations when contrasted to new variations, was obtained, even though Ss were performing almost without error upon completion of visual or haptic training. This inability of Ss to recognize intersensory equivalents of the training patterns when the intrasensory groups' performance clearly indicated that $S s$ had encoded specific dot-pattern information forces the conclusion that the dot patterns were encoded differently when presented visually and haptically.

It is not immediately obvious why Ss did not perform reliably better on OV when contrasted to new within-class patterns in either the $\mathrm{V}-\mathrm{H}$ or $\mathrm{H}-\mathrm{V}$ intersensory conditions, when several other studies have shown evidence to the contrary (Gaydos, 1956; Lobb, 1970; Shaffer \& Ellis, in press). A difference, however, between those studies finding evidence for intersensory transfer and the present study is that the former have used closed (curved or straight lined) figures that may be relatively easy to encode verbally. Indeed, Gaydos reported that Ss used verbal descriptors to encode some of the forms, and moreover, employed the same verbal labels for the forms when they were presented via the second sensory modality. Since the dot patterns used in the present study were judged by Es to be low in verbal codability, and assuming that verbal coding is the principle mechanism used to mediate the equivalence relationship of intersensory analogue stimuli, then the lack of intersensory transfer of specific information in the present study could be accountable due to Ss' inability to verbally encode the stimuli. This interpretation of course appeals to the mediational hypothesis.

With regard to Ss learning about schematic information, it will be recalled that although the $\mathrm{H} \cdot \mathrm{H}$ group did not evidence schema learning, the V.V group did "recognize" the CP reliably better than the new 5-bit variations. This finding replicates Posner and Keele's (1968) Experiment III and indicates that Ss learned the invariant features. It was thought that, since schemata represent the invariant or conceptual features of stimuli, this information would not be restricted to sensory modality and would, therefore, qualify as "higher order" information of the kind suggested by Gibson (1966). The present study indicates, however, that the manner by which Ss encode and represent this schematic information is specific to the sensory system by which the stimuli were presented, since the V.H group did not "recognize" the haptically presented CP. Furthermore, the ability of Ss to abstract schematic information may depend on the sensory modality by which the stimulus information is presented, since Ss in the H.H group did not evidence the ability to respond differentially to the CPs.

It should be pointed out that although no evidence was obtained for a common intersensory coding of particular pattern configurations or the population characteristics, Ss did learn something about the dot patterns that was not restricted to the mode of presentation, as given by above-chance performance on both old and new class patterns. Although no controls 
were included in the present study that would allow a specification of other sources of transfer, Ss could achieve above-chance performance by a common intersensory encoding of only certain aspects of the nominal patterns within each schema class. This type of transfer could be supported by previously learned common responses to these relatively "simple" features and, therefore, does not force an invariant features interpretation.

As was indicated in the introduction, a convergence between the mediational and invariant features hypotheses is made difficult for two main reasons: (1) the hypotheses as framed are not necessarily mutually exclusive and (2) direct support for the. mediational position can be interpreted as evidence in support of the invariant features hypothesis. That Holmgren, Arnoult, and Manning (1966) concur in this opinion is indicated by their statement, "At the present time there seems to be no way to design a critical experiment which would allow one to choose between the perceptual model and the mediational model." Under the conditions of the present study, however, it was argued that a demonstration of intersensory transfer of specific information would provide weak support for the invariant features hypothesis, while evidence for the invariancy of learned information about population characteristics, across sensory systems, would have provided even stronger support for the notion that there are sources of information not restricted to input modality. Direct support for the invariant features hypothesis was not obtained, since neither source of transfer was evidenced when the stimulus modality was changed.

\section{REFERENCES}

Bartlett, F. C. Remembering. Cambridge: Cambridge University Press, 1932.
Birch, H. G., Lefford. A. Intersensory development in children. Monograph of Sncial Research in Child Development, 1963, 28, No. 5 .

Blank, M., \& Bridger, W. H. Cross model transfer in nursery school children. Journal of Comparative \& Physiological Psychology, 1964, 58, 272-282.

Clark, J. L., Warm, J. S.. \& Schumsky, D. A. General and specific factors in the intersensory transfer of form. Journal of Experimental Psychology, 1972, 95, 184-188.

Evans, S. H. A brief statement of schema theory. Psychonomic Science, 1967, 8, 87-88.

Gaydos, $H_{2} F$. Intersensory transfer in the discrimination of form. American Journal of Psychology, 1956, 69, 107-110.

Gibson. E. J. Principles of perceptual learning and development. New York: Appleton-Century-Crofts, 1969.

Gibson, J. J. The senses considered as a perceptual system. Boston: Houghton, 1966.

Holmgren, G. L., Arnoult, M. D., \& Manning, W. H. Intermodal transfer in a paired-associate learning task. Journal of Experimental Psychology, 1966, 71, 254-259.

Krauthamer, G. M. An experimental study of form perception across sensory modalities. (Doctoral dissertation, New York University) Ann Arbor: University Microfilms, 1959. No. 64-11, 694.

Lobb, H. Asymmetrical transfer of form discrimination across sensory modalities in human adults. Journal of Experimental Psychology, 1970, 86, 350-354.

Posner, M. I. Abstraction and the process of recognition. In G. H. Bower and J. T. Spence (Eds.), The psychology of learning and motivation. New York: Academic Press, 1969.

Posner, M. I., Goldsmith, R., \& Welton. K. E. Perceived distance and the classification of distorted patterns. Journal of Experimental Psychology, 1967, 73, 28-38.

Posner, M. I Keele, S. W. On the genesis of abstract ideas. Journal of Experimental Psy chology, 1968, 77, 353-363.

Posner, M. I., \& Keele. S. W. Retention of abstract ideas. Journal of Experimental Psychology, 1970, 83, 304-308.

Riesen, A. H. The development of visual perception in man and chimpanzee. Science, 1947, 106, 107-108.

Senden, M. von. Space and sight: The perception of space and shape in the congenitally blind before and after operation. (Trans. P. Health) London: Methuen, 1960.

Shaffer, R. W., \& Ellis, K. C. An analy sis of intersensory transfer of form. Journal of Experim ental Psychology, in press.

Siegel, A. I. Deprivation of visual form definition in the ring dove. I. Discriminatory learning. Journal of Comparative \& Physiological Psychology, 1953, 46, 115-119.

Strange, W., Kenney, T., Kessel, F, S., \& Jenkins, J. J. Abstraction over time of prototypes from distortions of random dot patterns: A replication. Journal of Experimental Psychology, 1970, 83, 508-510.

Wright, J. M. Cross-modal transfer and sensory equivalence-A review. Scandinavian Journal of Psychology, 1970, 11, 22-30.

(Received for publication August 13, 1973; revision received September 19, 1973.) 